\title{
WW domain-containing FBP-30 is regulated by p53
}

\author{
Valerie Depraetere ${ }^{1}$ and Pierre Golstein ${ }^{\star, 1}$ \\ ${ }^{1}$ Centre d'Immunologie INSERM-CNRS de Marseille-Luminy, Case 906, 13288 \\ Marseille Cedex 9, France \\ * corresponding author: Dr. Pierre Golstein, Centre d'Immunologie INSERM- \\ CNRS de Marseille-Luminy, Case 906, 13288 Marseille Cedex 9, France. \\ tel: +33 491269468; fax: +33 491269430; e-mail: golstein@ciml.univ-mrs.fr
}

Received 24.3.99; revised 17.6.99; accepted 13.7.99

Edited by B. Osborne

\begin{abstract}
A subtractive cloning approach was used to clone genes transcriptionally induced in thymocytes undergoing programmed cell death after $\gamma$-irradiation. We thus identified about 60 upregulated genes. One of these genes encodes a WW domain previously briefly reported by others, which defines this gene as FBP-30. CDNA sequencing showed FBP30 to be remarkably conserved in mammals. FBP-30 expression, essentially restricted to $T$ cells, was regulated by p53 since it increased (1) after $\gamma$-irradiation in wild-type but not in p53- $I-$ thymocytes and (2) in cells transfected with a conditional temperature-sensitive p53 mutant, less than $1 \mathrm{~h}$ after shifting to permissive temperature. Upregulation of FBP30 expression thus depends upon p53 protein expression and correlates with cell death induction in these systems. While the kinetics of its induction are rapid, the observed increased expression of FBP-30 in the presence of protein synthesis inhibitors suggests that FBP- 30 gene expression is indirectly regulated by $\mathrm{p} 53$, through downregulation of a labile inhibitor of FBP-30 expression.
\end{abstract}

Keywords: $\gamma$-irradiation; p53; subtractive cloning; FBP-30; WW domain

Abbreviations: ActD, actinomycin D; AlF, apoptosis inducing factor; BLAST, basic local alignment search tool; ConA, concanavalin $\mathrm{A} ; \mathrm{CHX}$, cycloheximide; DR5, death receptor 5; est, expressed sequence tags; Fas-L, Fas ligand; FBP-30, formin binding protein 30; $\mathrm{Fc} \gamma \mathrm{R}$, receptor for the constant fragment of gamma immunoglobulins; FCS, foetal calf serum; HMG, high mobility group; IL-1 $\beta$, interleukine 1 beta; IL2R, interleukine 2 receptor; Irr, irradiated; Id, limb deformity; LPS, lipopolysaccharide; MAPKKK, mitogen activated kinase kinase kinase; oligodT, oligodeoxy thymidinetriphosphate; ORF, open reading frame; PCD, programmed cell death; PCR, polymerase chain reaction; PDGF-R, platelet derived growth factor receptor; PI 3K, phosphoinositol 3 kinase; PLA2, phospholipase A2; RACE, rapid amplification of CDNA ends; RDA, representational difference analysis; RT-PCR, reverse transcription coupled polymerase chain reaction; TGF, transforming growth factor; TNF, tumour necrosis factor; XRCC, X-ray cross-complementing group

\section{Introduction}

Subtractive approaches might be appropriate to clone cell death signalling genes in systems where PCD is dependent on RNA synthesis, ${ }^{1-6}$ whereas many of the genes encoding the cell death machinery, which is thought to be constitutively expressed in all cells, ${ }^{7}$ would not be identified by such a procedure. The aim of the present study was to look for genes the expression of which is induced upon $\gamma$-irradiation and may lead to activation of the cell death program. Thymocytes were chosen as a model because of their high sensitivity to $\gamma$ irradiation, and because $\gamma$-irradiation-induced death of thymocytes is dependent upon p53 expression and upon RNA and protein synthesis. ${ }^{3,4}$ A subtractive cloning approach was developed to clone genes which are up-regulated in $\gamma$ irradiated- as compared to untreated-wild-type murine thymocytes. Thirty-one known genes were identified in this screen, along with 28 new gene fragments. Some of the former had previously been reported to be induced by $\gamma$ irradiation, which validates our screening procedure. The relevance of the other known genes to our screening will be briefly discussed. One gene, FBP-30, was studied in more detail. A 26 amino-acid proline-rich binding WW domain defining FBP-30 has been briefly reported. ${ }^{8}$ Importantly, WW domains have recently been shown to bind to phosphoserineor phosphothreonine-containing proteins. ${ }^{9}$ We found the sequence of FBP-30 to be strikingly conserved in mammals, suggesting that the sequence of the entire protein is important for its function. In agreement with our cloning procedure, expression of this gene was found to be increased after $\gamma$ irradiation, moreover in a p53-regulated manner.

\section{Results and Discussion \\ Differential screening procedure}

Representational Difference Analysis (RDA, $\left.{ }^{10} \mathrm{CLONTECH}\right)$ is a subtractive cloning approach based on the selective amplification by competitive PCR of cDNA fragments corresponding to genes which are expressed at a higher level in a given population as compared to another population. We used RDA to subtract untreated wild-type thymocyte cDNA from irradiated thymocyte cDNA. The subtraction products were cloned; the approximately 5000 corresponding clones were ordered on high density filters, and successively hybridized with complex probes made out of total RNA isolated from either irradiated or untreated thymocytes by reverse transcription, in order to confirm their differential expression pattern. The hybridization signals were quantified, normalized by comparison with a vector control probe, and compared as described. ${ }^{11}$ The 400 clones which were confirmed to be differentially expressed by this technique and 10 clones which were below detection limits were further studied. Since RDA produces small cDNA fragments, pools (80-90 clones) of these subtraction products were used as probes to screen an irradiated- 
thymocyte phage cDNA library in order to obtain longer cDNA clones corresponding to these RDA products. The latter clones were ordered on high density filters, screened by successive hybridization with complex probes as before and cross-hybridized to screen for redundancy. Sixty nonredundant clones were thus identified and sequenced at their $5^{\prime}$ and/or $3^{\prime}$ end. Thirty-one of them corresponded to known genes (Table 1), 28 were found to be unknown, and one clone was studied in more details. This clone encodes a protein, FBP-30, which includes a previously reported 26 amino-acid WW domain. ${ }^{8}$

\section{Screening results}

The 31 known genes which were identified in our screen for genes induced in mouse thymocytes after $\gamma$-irradiation can be grouped in five categories (Table 1). Group A corresponds to genes known to be induced by $\gamma$-irradiation or other DNA damaging stresses, such as XRCC-1, HMG-1 or $c-m y c,^{12-14}$ and thus to some extent validates the screening procedure. Group B genes encode phospholipases and kinases, which have been involved in some instances of cell death or cell survival such as PI3kinase, ${ }^{15}$ MAPKKK, ${ }^{16}$ PLA2. ${ }^{17}$ Phospholipases and kinases can thus be regulated at the transcriptional level upon cell death induction. ${ }^{18,19}$ Group C includes molecules with functions in

Table 1 Sequences identified in the screen for irradiation-induced genes

\begin{tabular}{l} 
A. DNA-damage-induced genes \\
XRCC1 \\
HMG1 \\
ATP-dependent RNA helicase \\
oxidative stress-induced protein \\
C-myc \\
B. Signal transduction molecules \\
PLA2 \\
p56tek \\
MAPKKK \\
PI3kinase \\
C. Molecules of the immune system \\
41 BB \\
FC $\gamma$ RII \\
B7.2 \\
TCR $\alpha / \delta$ \\
IL2p35 \\
D. Mitochondrial molecules \\
mitochondrial DNA \\
cytp450 \\
cytochrome oxidase \\
cytb \\
E. Others \\
RAR $\alpha$-regulated gene \\
blimp1 \\
adipose fatty acid binding protein \\
L1 repeat \\
lens epithelial protein bach 1 \\
van Willebrandt factor \\
VP7 \\
MyoD \\
TGF $\beta$ \\
\hline
\end{tabular}

the immune system, some of which have also been involved in the control of cell death (IL2Rp35, ${ }^{20} \mathrm{Fc} \gamma \mathrm{RII},{ }^{21}$ and IL $1 \beta)$. Group D consists of molecules, either mitochondrially encoded, or mitochondrially located. This might be related to an increase in respiration after an irradiation stress, or to the involvement of mitochondrial products such as cytochrome $\mathrm{C}$ and AIF in the control of cell death. ${ }^{22,23}$ Finally, group $\mathrm{E}$ includes diverse genes, some of which have been involved in the control of cell death, such as Blimp- $1^{24}$ or TGF $\beta^{6}$ which can potentialize p53-induced cell death. ${ }^{25}$ The region of Blimp- 1 which is critical for its cell death inducing properties is a 69 amino acid proline-rich region. ${ }^{24}$ This is interesting in the light of the identification in our screen of FBP-30, a protein bearing a WW domain known to interact with proline-rich regions.

Our screen has thus identified a number of candidate regulators of $\gamma$-irradiation and p53 induced cell death, outside of the known p53 regulated (such as c-myc) or regulating (such as HMG-1 and $\mathrm{TGF} \beta$ ) molecules. It did not, however, include other p53 induced genes such as Bax, Fas, DR5, or genes identified by differential screening in fibroblasts expressing a thermosensitive p53 mutant allele. $^{18,26}$ This is most likely due to the respective biases of the differential screening (differential display) and subtractive cloning (RDA) procedures, as well as to the biological systems used.

\section{FBP-30 expression in untreated and in $\gamma$-irradiated thymocytes}

One of the clones identified in our subtractive cloning in $\gamma$ irradiated thymocytes encodes a protein known as Formin Binding Protein-30 since it includes a Formin binding WW domain. Only the 26 amino-acid sequence corresponding to this WW domain has been published. ${ }^{8}$ In line with the subtractive cloning, we found by Northern blot analysis that FBP-30 mRNA was up-regulated in thymocytes upon irradiation: FBP-30 mRNA, expressed at a basal level in untreated wild-type thymocytes, is detectably increased $1 \mathrm{~h}$ after irradiation, peaks $1-2 \mathrm{~h}$ after irradiation to ten times the level of expression in untreated thymocytes, on average, and declines thereafter (Figure 1). A single $4 \mathrm{~kb}$ transcript could be detected (Figure 1). Increased expression of FBP-30 mRNA after irradiation was also confirmed by semi-quantitative RT-PCR (not shown). FBP-30 expression was not increased by other death-inducing agents such as anti-Fas antibodies, anti-CD3 antibodies, dexamethasone or methotrexate (not shown). Among adult tissues, FBP-30 mRNA could be detected on Northern blots in thymus and uterus, in a $\mathrm{T}$ cell hybridoma $\left(\mathrm{L} 16.24^{27}\right)$, and also in ConA-activated but not LPSactivated splenocytes. The increased expression of FBP30 in ConA-activated splenocytes might reflect induction of FBP-30 expression upon activation of $\mathrm{T}$ cells, or upon death of $\mathrm{T}$ cells after ConA-activation; alternatively, it might reflect enrichment of FBP-30 expressing $\mathrm{T}$ cells after ConA treatment of splenocytes. FBP-30 mRNA could be detected in mouse embryos as early as 9 d.p.c. and was undetectable on Northern blots of adult brain, heart, liver, lung, spleen and kidney (not shown). 


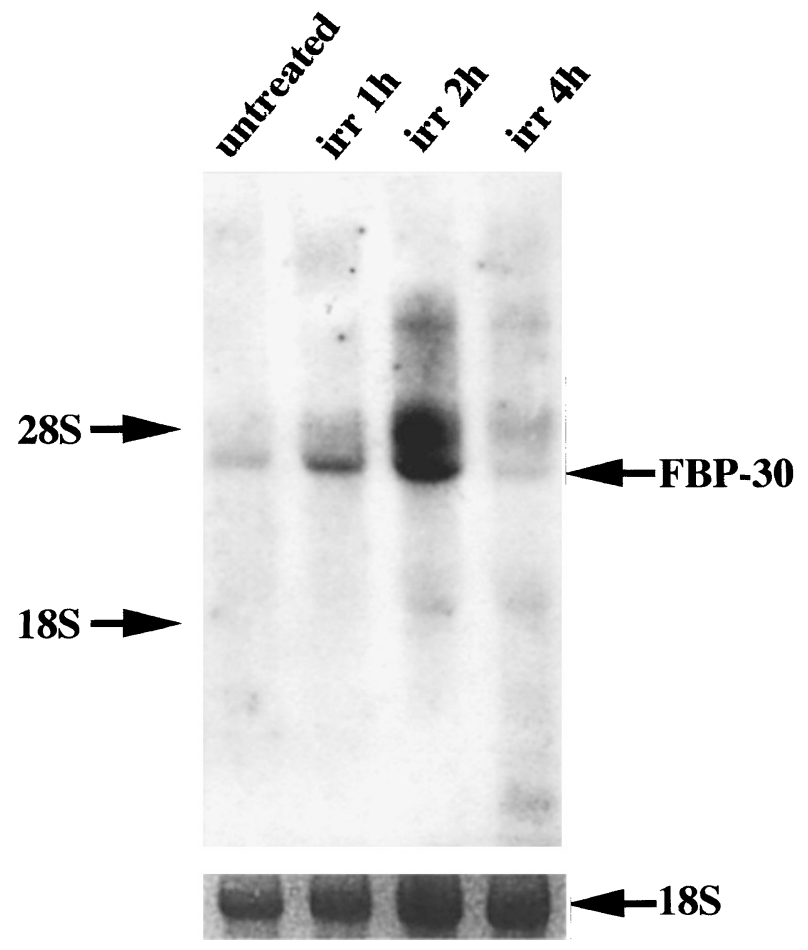

Figure 1 Upregulation of FBP-30 expression in thymocytes by $\gamma$-irradiation. Total RNA was purified from wild-type B6 thymocytes before or 1, 2 or $4 \mathrm{~h}$ after 5 Gray $\gamma$-irradiation, run on a formaldehyde gel, blotted on nitrocellulose membrane, and hybridized with mouse FBP-30 cDNA. The 18S RNA band is shown as a control of uniform gel loading

\section{FBP-30 is a p53-regulated gene}

FBP-30 mRNA levels were found to be increased upon $\gamma$ irradiation, known to upregulate the transcription factor p53 in thymocytes. ${ }^{3}$ We therefore sought whether the increase in FBP-30 expression we observed was p53-dependent.

Northern blot analyses showed that while FBP-30 mRNA levels were increased after irradiation in wild-type thymocytes, they were unaffected or even decreased after irradiation in p53-1- thymocytes (Figure 2A). Thus, p53 appears to be necessary for the irradiation-induced increase in FBP-30 mRNA levels. However, p53 appears to be dispensable for FBP-30 constitutive gene expression since FBP-30 mRNA could be detected in untreated p53-/- thymocytes at a level equivalent or even superior (in some experiments) to that detected in wild-type thymocytes (Figure 2A). Furthermore, using cells transfected with a thermosensitive mutant of $p 53,{ }^{28}$ we could show that expression of the wild-type p53 protein leads to an increase in FBP-30 mRNA levels. LTRC13 cells cultured at non-permissive temperature $\left(38^{\circ} \mathrm{C}\right)$ express a mutant form of the p53 protein and do not express detectable amounts of FBP-30 mRNA. At permissive temperature $\left(32^{\circ} \mathrm{C}\right)$, however, the p53 protein is in wild-type configuration and translocates to the nucleus. A FBP-30 transcript could be detected in LTRC13 cells after $1 \mathrm{~h}$ incubation at $32^{\circ} \mathrm{C}$ (Figure $2 \mathrm{~B}$ ).

An increase in FBP-30 expression thus correlates with p53 protein expression and cell death induction in p53deficient cells and in cells expressing a thermosensitive

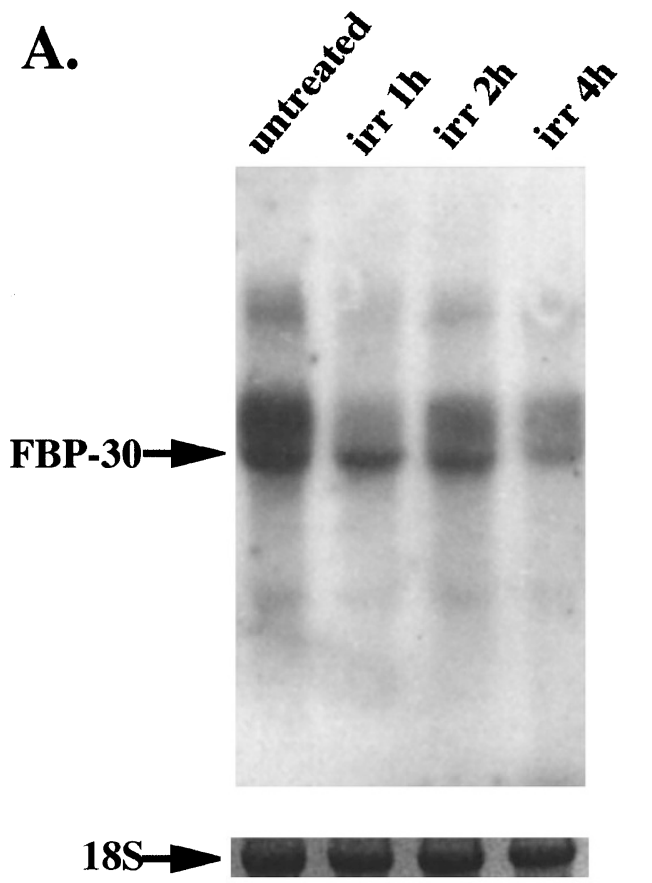

B.

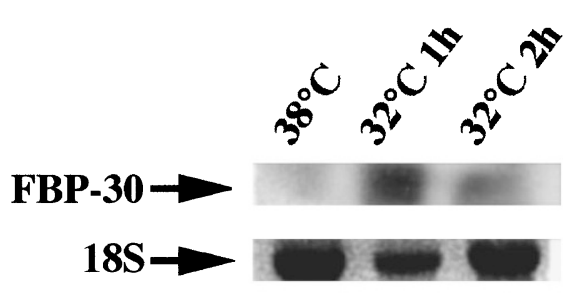

C.

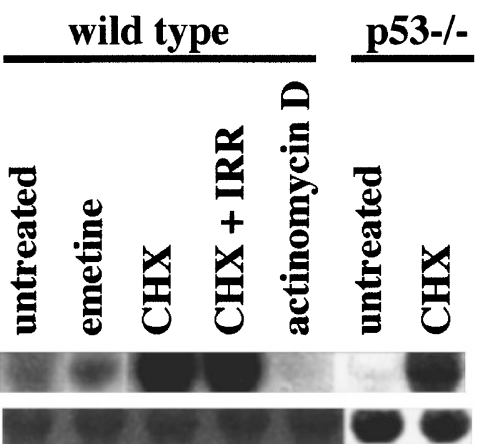

Figure 2 FBP-30 mRNA expression is regulated by the p53 protein and increased by protein synthesis inhibitors. Northern blot analysis was performed as described in Figure 1, using (A) p53-/ - thymocytes, (B) LTR-C13 cells cultured at $38^{\circ} \mathrm{C}$ and shifted to $32^{\circ} \mathrm{C}$ for 0,1 or $2 \mathrm{~h}$ before RNA extraction, and (C) wild-type and p53-l- thymocytes treated with actinomycin D $0.1 \mu \mathrm{g} / \mathrm{ml}$, cycloheximide $1 \mu \mathrm{g} / \mathrm{ml}$ or emetine $10 \mu \mathrm{g} / \mathrm{ml}$ for $3 \mathrm{~h}$ and $/$ or with 5 Gray $\gamma$-irradiation 
mutant of p53. The kinetics of its induction by p53 suggests that the FBP-30 gene could be a direct target for the p53 protein. While inhibition of transcription by Actinomycin $\mathrm{D}(0.1 \mu \mathrm{g} / \mathrm{ml})$ predictably resulted in a slight decrease in FBP-30 mRNA levels, inhibition of translation by cycloheximide $(1 \mu \mathrm{g} / \mathrm{ml})$ or less so by emetine $(10 \mu \mathrm{g} /$ $\mathrm{ml}$ ) for $3 \mathrm{~h}$ resulted in an increase in FBP-30 signal on Northern blots of both wild-type and p53-/- thymocytes (Figure 2C). This suggests that a labile protein normally interferes with FBP-30 transcription. The effect of p53 on FBP-30 expression may thus be secondary to the repression by $\mathrm{p53}$ of such a labile inhibitor of FBP-30 transcription.

\section{FBP-30 shows remarkable sequence conservation in mammals}

The mouse FBP-30 clone isolated in our screen was $2.3 \mathrm{~kb}$ long and included a $1.5 \mathrm{~kb}$ ORF encoding a highly soluble protein, rich in lysine, serine and glutamic acid residues (Figure 3A). The cDNA was further extended by successive $5^{\prime}$ RACE experiments to $2.5 \mathrm{~kb}$ (Figure $3 \mathrm{~A}$ ). This is to be compared to the $4 \mathrm{~kb}$ transcript reported above (Figure 1). We have been unable to clone the $5^{\prime}$ end of the corresponding cDNA either by screening nine distinct cDNA libraries (five thymus, one thymoma, one placenta, two total embryo libraries), or by further repeated 5' RACE attempts (not shown), possibly because of the high CG content of this CDNA end (Figure $3 \mathrm{~A})$.

The sequence of mouse FBP-30 cDNA was found to be strikingly homologous to human and rat est clones. The derived mouse protein sequence is $94 \%$ identical and $98 \%$ homologous to the conceptual translation of the available human est clones (Figure 3B). Such remarkable sequence conservation suggests that the sequence of the corresponding protein on most of its length is critical for its function.

\section{FBP-30 bears a WW domain}

The protein corresponding to the FBP-30 cDNA bears the previously reported ${ }^{8} 26$ amino-acid WW domain (underlined in Figure 3A). WW domains are tryptophan-rich motifs which bind proline-rich regions called $\mathrm{FH} 1$ domains $^{29,30}$ or phosphoserine residues. ${ }^{9}$ Interestingly, FBP-30 itself bears a proline rich region (underlined with a dashed line in Figure $3 A)$. The WW domain and the proline rich region of FBP-30 might thus interact, either intramolecularly, or intermolecularly, which would lead to dimerization. Association of FBP-30 with other partners might thus be regulated by changes in the concentration or in the conformation of FBP-30.

Many WW domain-containing proteins and WW domainbinding proteins ( $\mathrm{FH}$ domain-containing proteins) are associated with the cytoskeleton. WW domain- and $\mathrm{FH}$ domain-containing proteins seem to function as a scaffold to recruit multiple proteins locally at the level of the cytoskeleton, thus inducing reorganization of the cytoskeleton, signal transduction, or polarization of the cell. ${ }^{31-33} \mathrm{~A}$ role of FBP-30 in disorganization of the cytoskeleton which occurs in dying cells might thus be hypothesized.
The 26 amino-acid WW domain of FBP-30 was initially isolated in a screen for proteins binding the proline-rich region of Formin. $^{8}$ Mice deficient in formin (Id mutants) show bone fusions in the limbs and renal aplasia, ${ }^{34}$ which might be due to a defect in polarization of the limb- and the uretic-buds. $^{35}$ The phenotype of Id mutants is remarkably similar to that of heterozygous mutants of the Oligosyndactyly gene. In these mutants, the movements of the mitotic spindle are impaired. ${ }^{36}$ This suggests that the phenotype of Id mutants might be secondary to alterations of the cytoskeletal architecture. Interestingly, 'necrotic' mesenchymal cells have been observed in the limb buds of Id mice. ${ }^{37}$ Furthermore, overexpression of formin seems to be toxic to HeLa and NIH-3T3 cells. ${ }^{38}$ This suggests a role for formin in the control of cell death in the developing limb bud and kidney. Cell death might be a cause or a consequence of the defects in cytoskeletal organization and polarization. FBP-30 might play a similar role, by interacting with Formin. However, in preliminary experiments, transient transfection with the available FBP-30 CDNA or with fusion proteins of the WW domain of FBP-30 (which might be expected to function as a dominant negative inhibitor of FBP-30 by disrupting the interactions of FBP-30 with its partners) altered neither viability nor susceptibility to staurosporine-induced cell death of fibroblasts or $\mathrm{T}$ cell hybridomas. A systematic investigation should be performed e.g. in thymocytes, treated with $\gamma$ irradiation and other cell death inducing agents, in order to provide more definitive conclusions as to the possible involvement of FBP-30 in the regulation of cell death. That some cell death signals might be transduced via FBP-30 is not unlikely in view of the WW dependence of some PDGFR-mediated survival signals. ${ }^{39}$ More generally, the control by $\mathrm{p} 53$ of FBP-30, a molecule containing a WW domain and thus likely to interact with other proteins as a function of their level of phosphorylation, ${ }^{9}$ may suggest p53-induced regulation of a signalling pathway.

\section{Materials and Methods}

\section{Mice, cells and reagents}

All cells were cultured in RPMI 1640 supplemented with 10\% FCS, $200 \mathrm{mM}$ glutamine, $200 \mathrm{mM}$ sodium pyruvate, $1 \times$ non-essential amino acid solution (all purchased from Gibco BRL Life Technologies, Gaithersburg, MD, USA), and $25 \mu \mathrm{M} \beta$-mercaptoethanol (Calbiochem, La Jolla, CA, USA) at $37^{\circ} \mathrm{C}$ in $5 \% \mathrm{CO}_{2}$. All organs were isolated from 4-8-week-old female B6 mice. Thymocytes received 0.5 Gray $\gamma$-irradiation (CIS bio international SA, Saclay, France) and were thereafter incubated at $37^{\circ} \mathrm{C}$ for 1,2 or $4 \mathrm{~h}$ for RNA analysis, and 4,6 or $8 \mathrm{~h}$ for protein analysis. Splenocytes were activated with $1.5 \mu \mathrm{g} / \mathrm{ml}$ ConA for $48 \mathrm{~h}$ or $5 \mu \mathrm{g} / \mathrm{ml}$ LPS for $72 \mathrm{~h}$. Engineered p53 deficient mice, L16.24 and LTRC1-3, Jo2 anti-Fas antibody and $C 45-2 C 11$ anti- $C D_{3}$ antibody have been described. ${ }^{4,27,28,40,41}$ Mitomycin C, emetine, cycloheximide, doxorubicin, concanavalin A and LPS were purchased from Sigma-Aldrich Inc., St Louis, MO, USA. Methotrexate was purchased from Ledertrexate, Mexico. 
A

ACGTCTCCCGCGGTGCCTGCCACCGCTGCCCCAGAGGACTCGCCTTCAGAAGATGAACAGCGAAGTGGTGGTGGAATCCCAAACGTTGTCCAGAATCCTCCCAAACCAGTCATGCCCAC

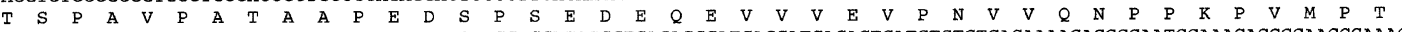

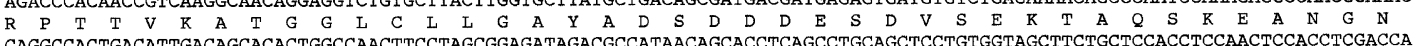
CAGGCCACTGACATTGACAGCACACTGGCCAACTTCCTAGCGGAGATAGACGCCATAACAGCACCTCAGCCTGCAGCTCCTGTGGTAGCTTCTGCTCCACCTCCAACTCCACCTCGACCA

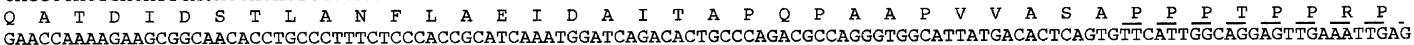

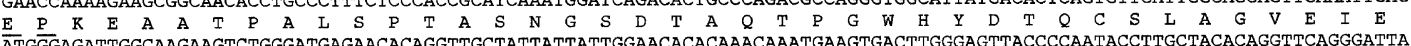
ATGGGAGATTGGCAAGAAGTCTGGGATGAGAACACAGGTTGCTATTATTATTGGAACACACAAACAAATGAAGTGACTTGGGAGTTACCCCAATACCTTGCTACACAGGTTCAGGGATTA CAACATTACCAGCCCAGTTCTGTAACAGGTACCGAGGCTGCTTTTGTGGTAAATACAGACATGTATACAAAGGAGAGGACAACTGCTGCTTCCAGTAGTAAAAGTGGACCAGTCATCACC

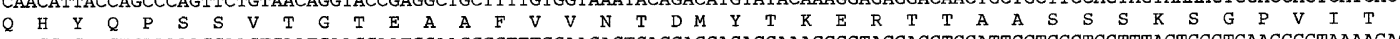
AAACGAGAAGTTAAAAAGGAAGTGAATGAAGGAATCCAAGCCCTTTCCAACAGTGAGGAGGAGAGGAAAGGGGTAGCAGCTGCATTGCTCGCTCCTTTACTGCCTGAAGGGGTAAAAGAG

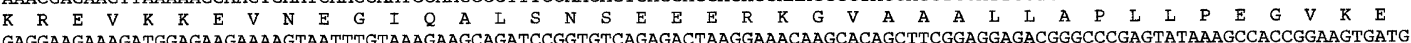

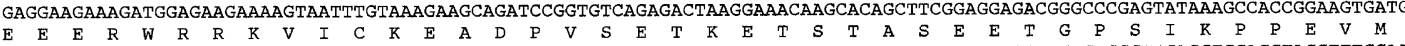
ATGACGGCACAGAAA

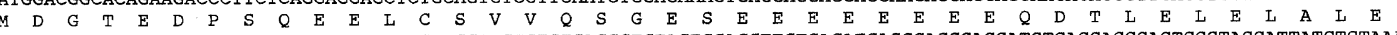
AGGAAAAAGGCAGAGTTACGAGCCTTGGAGGAAGGAGATGGTAGTGTGTCAGGGTCTAGTCCACGTTCTGACATCAGCCAGCCAGCATCTCAGGACGGAGTGCGTAGGATTATGTCTAA

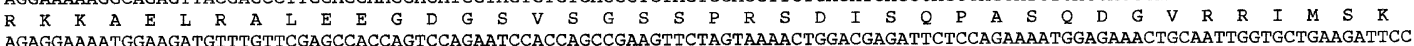

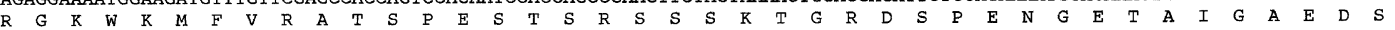

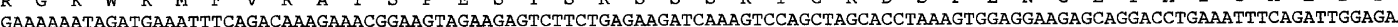

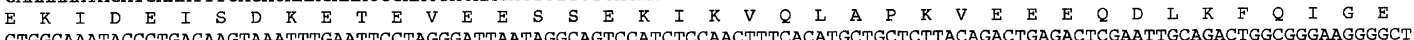

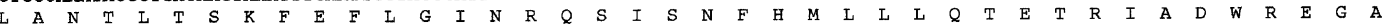
CTCAATGGAAATTACCTAAAACGAAAGCTTCAGGATGCTGCAGAACAGCTAAAACAGTATGAAATAAACGCCACTCCTAAAGGCTGGTCCTGCCACTGGGACAGGACCTCTGGAAGCAA $\begin{array}{lllllllllllllllllllllllllllllllllllllllllll}L & N & G & N & Y & L & K & R & K & L & Q & D & A & A & E & Q & L & K & Q & Y & E & I & N & A & T & P & K & G & W & S & C & H & W & D & R & T & S & G & S & N\end{array}$ TACTCCTGATTAACCTCGGTGAAGTTAAGGAAAACTTCGTGACTGCAGAAGTGAATGAAGAACAAGATTACTATCCTCTGCCAGCAGGGATCATAGACGATATTTCTATGTAAACGAACA

Y S AAACTCTACAGAATCCTCTGAGAACCCGACAGGTAAGACAGTTTATTCTGTTCTAGTAGAACAATAGCTTTAGAGAAAAGAACATCAGTTTTTTTATTTATAGGACAACTTATAGCATAG AATAACATGCTAATTGAAGTCCAACTTAAACTGTGACAACACACGAGTTTGCTAAAAGGAATTAAGTCAATGTATCAGTCTGCCATCAAAGTAAAAAAATAAAATGCTACCT'TTTGATCT TAAAATATTTCATGCACTGAATATTAATTAATACATGTTTTGTGTACTCTGTTAGTAAGTACAAATTTTTATGTATCAAACAAAAATAATTCATAGGGCTGGAGAGATGGCTCAGTGGTTA AGAGCACTGGATGCTCTCTCACAGGTCCTGAGTTCAGTTCCCAACAGCCACATGGTGGCTCACAACCATCGGTAATAGAATCCGATGCCCTCCTCTCATGTGAACTCATAAAAAATTTTA AAATGGAAAAAAAAAAAAAAAAAA

B

Mouse FBP-30 TSAPAVPATAAPEDSPSEDEQEVVVEVPNVVQNPPKVMPTRPTTVKATGGLCLLGAYADSDDDESDV Human/rat est $\left\{\begin{array}{l}(\text { AA817853) }-\mathrm{N}-\mathrm{I} \\ -(\mathrm{AA3} 313994)-\mathrm{QN}-\end{array}\right.$

Mouse FBP-30 SEKTAQSKEANGNQATDIDSTLANFLAEIDAITAPQPAAPVVASAPPPTPPRPEPKEAATPALSPTASNG

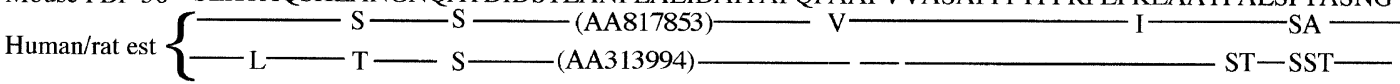

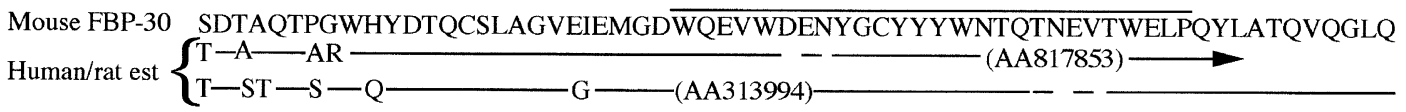

Mouse FBP-30 HYQPSSSVTGTEAAFVVNTDMYTKERTTAASSSSKSGPVITKREVKKEVNEGIQALSNSEEERKGVAA

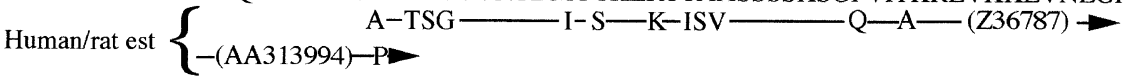

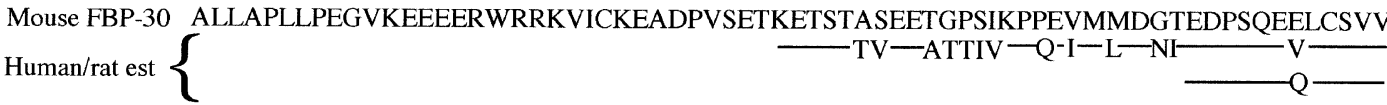

Mouse FBP-30 QSGESEEEEEEEEQDTLELELALERKKAELRALEEGDGSVSGSSPRSDISQPASQDGVRRIMSKRGKW

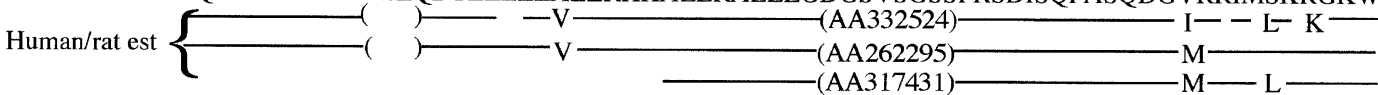

Mouse FBP-30 KMFVRATSPESTSRSSSKTGRDSPENGETAIGAEDSEKIDEISDKETEVEESSEKIKVQLAPKVEEEQDL

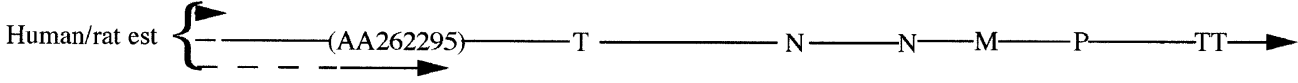

Mouse FBP-30 KFQIGELANTLTSKFEFLGINRQSISNFHMLLLQTETRIADWREGALNGNYLKRKLQDAAEQLKQYEI Human/rat est

Mouse FBP-30 NATPKGWSCHWDRTSGSNYS

Human/rat est $\left\{\begin{array}{l}\text { (AA828106) } \\ \text { (AA3123126) }\end{array}\right.$

Figure 3 Mouse FBP-30 cDNA and protein partial sequences and homologies with human and rat est clones. (A) Mouse FBP-30 cDNA and protein partial sequences: The WW domain previously described ${ }^{8}$ is underlined. A proline rich region is underlined with a dashed line. (B) Alignment of mouse FBP-30 protein sequence with translated human est clones AA313994 (the whole length of the est), AA262295 (nucleotides $13-438$ of the est), Z36787 (the whole length of the est), AA317431 (nucleotides 1-77 of the est), AA332524 (the whole length of the est), AA828106 (nucleotides $384-369$ of the est) and rat est clone AA817853 (the whole length of the est). Residues which are not conserved between mouse FBP-30 and human or rat est clones are shown. Dashed lines indicate frame shifts. Arrows indicate $5^{\prime}$ to $3^{\prime}$ orientation of the est. ( ) indicates a gap in the alignment. The WW domain is overlined 


\section{Subtractive screening}

Total RNA was extracted by Trizol (Gibco BRL). PolyA+ RNA was isolated with FastTrack (Invitrogen, Leek, The Netherlands). Northerns and RT-PCR were performed as described. ${ }^{42,43}$ Two $\mu \mathrm{g}$ polyA+ mRNA from untreated and irradiated thymocytes (pools of RNA isolated from thymocytes 1,2 and $4 \mathrm{~h}$ after irradiation) were used to perform Representational Difference Analysis $\left(\mathrm{RDA}^{10}\right.$ using Clontech's PCR select cDNA subtraction kit (Clontech, Palo Alto, CA, USA). The RDA products were cloned into pGEM-T vector (Promega Corp., Madison, WI, USA). High density filter generation and hybridization were performed as described. ${ }^{11}$

\section{cDNA cloning}

Two $\mu \mathrm{g}$ polyA+ mRNA pooled from thymocytes incubated for 1,2 and $4 \mathrm{~h}$ after irradiation were used to generate a cDNA library in $\lambda Z A P$ express (Stratagene, La Jolla, CA, USA). The library was transferred onto nylon membranes (Dupont NEN, Boston, MA, USA) and hybridized in $\mathrm{CHURCH}$ buffer. Three other CDNA libraries derived from an adult thymus, ${ }^{11}$ a foetal (day 15) thymus (Lefkovits et al., Basel Institute for Immunology, Switzerland), and a day 13.5 embryo library (Novagen, Madison, WI, USA) respectively, were screened by hybridization. Five Marathon cDNA libraries (CLONTech Laboratories Inc., Palo Alto, CA, USA), namely one (day 15) mouse embryo commercial library, and four home made libraries (from mouse thymus, oligodT-primed, mouse thymus, random hexamer-primed, mouse placenta, oligodT-primed, and BW thymoma, oligodT-primed) were screened by PCR using a reverse oligonucleotide specific for the WW domain of FBP-30 (AAAGAATTCGGTAACTCCCAGTCACTTC):. 5' RACE was performed according to the manufacturer's instructions (Gibco BRL). Oligos CATGACTGGTGTTGGAGGGTTCTGAACGTTG, AGTCCTCTGGGGCAGCGGAG, GGCGAAGTTGTCCTCCCCATTGT were used successively.

Non redundant databases were screened by BLAST $n^{44}$ using a partial FBP-30 cDNA as a query. This provided the human and rat est clones shown in Figure 3. Also, the $3^{\prime}$ end of a rat est clone (AA817853) was found to have $89 \%$ homology with FBP-30. An oligonucleotide corresponding to the $5^{\prime}$ sequence of the rat clone (CAAACGTTGTCCAGAATCCTCCCAAAC) was used in combination with a $3^{\prime}$ oligonucleotide corresponding to the mouse sequence of FBP-30 (TAAGCACCAAGTAAGCACAGACCTGG) to amplify the mouse homologue of this est clone, thus contributing to extend the FBP-30 ORF $5^{\prime}$.

\section{Acknowledgements}

This work was supported by institutional grants from INSERM and CNRS and by additional grants from ARC and LNCC. V Depraetere was supported by fellowships from MESR and from FRM. We thank $E$. YonishRouach for providing us with a p53 cDNA probe and the LTRC1-3 cells, and for discussion, B. Jordan's group for helping us with the high density filter quantitative hybridization technology, and A. Miazek for providing us with four home made Marathon cDNA libraries.

\section{References}

1. Wyllie AH, Morris RG, Smith AL and Dunlop D (1984) Chromatin cleavage in apoptosis: association with condensed chromatin morphology and dependence on macromolecular synthesis. J. Pathol. 142: 67-77

2. Kastan MB, Onyekwere O, Sidransky D, Vogelstein B and Craig RW (1991) Participation of $\mathrm{p} 53$ protein in the cellular response to DNA damage. Cancer Res. 51: $6304-6311$
3. Lowe SW, Schmitt EM, Smith SW, Osborne BA and Jacks T (1993) p53 is required for radiation-induced apoptosis in mouse thymocytes. Nature 362 : 847-849

4. Clarke AR, Purdie CA, Harrison DJ, Morris RG, Bird CC, Hooper ML and Wyllie AH (1993) Thymocyte apoptosis induced by p53-dependent and independent pathways. Nature $362: 849-852$

5. Liu Z-G, Smith SW, McLaughlin KA, Schwartz LM and Osborne BA (1994) Apoptotic signals delivered through the $T$ cell receptor of a T-cell hybrid require the immediate-early gene nur77. Nature $367: 281-284$

6. Massagué J (1996) TGF beta signaling: receptors, transducers, and Mad proteins. Cell 85: 947-950

7. Jacobson MD, Weil M and Raff MC (1997) Programmed cell death in animal development. Cell 88: 347-354

8. Chan DC and Leder $P$ (1996) Genetic evidence that formins function within the nucleus. J. Biol. Chem. 271: 23472-23477

9. Lu PJ, Zhou XZ, Shen M and Lu KP (1999) Function of WW domains as phosphoserine- or phosphothreonine-binding modules. Science 283: 13251328

10. Hubank $M$ and Schatz DG (1994) Identifying differences in mRNA expression by representational difference analysis of cDNA. Nucleic Acids Res. 22: 56405648

11. Bernard K, Auphan N, Granjeaud S, Victorero G, Schmitt-Verhulst AM, Jordan BRand Nguyen C (1996) Multiplex messenger assay: simultaneous, quantitative measurement of expression of many genes in the context of $\mathrm{T}$ cell activation. Nucleic Acids Res. 24: 1435-1442

12. Thompson LH (1991) Properties and applications of human DNA repair genes. Mutat. Res. 247: 213-219

13. Jayaraman L, Moorthy NC, Murthy KG, Manley JL, Bustin M and Prives C (1998) High mobility group protein-1 (HMG-1) is a unique activator of p53. Genes Dev. 12: $462-472$

14. Evan G, Harrington E, Fanidi A, Land H, Amati B and Bennett M (1994) Integrated control of cell proliferation and cell death by the c-myc oncogene. Philos. Trans. $R$ Soc. Lond. B Biol. Sci. 345: 269-275

15. Del Peso L, Gonzalez-Garcia M, Page C, Herrera R and Nunez G (1997) Interleukin-3-induced phosphorylation of BAD through the protein kinase Akt. Science 278: 687-689.

16. Downward J(1998) Ras signalling and apoptosis. Curr. Opin. Genet. Dev. 8:4954

17. Jaattela M, Benedict M, Tewari M, Shayman JA and Dixit VM (1995) Bcl-x and $\mathrm{Bcl}-2$ inhibit TNF and Fas-induced apoptosis and activation of phospholipase A2 in breast carcinoma cells. Oncogene 10: 2297-2305

18. Amson RB, Nemani M, Roperch JP, Israeli D, Bougueleret L, Le Gall I, Medhioub M, Linares-Cruz G, Lethrosne F, Pasturaud P, Piouffre L, Prieur S, Susini L, Alvaro V, Millasseau P, Guidicelli C, Bui H, Massart C, Cazes L, Dufour F, Bruzzoni-Giovanelli H, Owadi H, Hennion C, Charpak G, Dausset J, Calvo F, Oren M, Cohen D and Telerman A (1996) Isolation of 10 differentially expressed cDNAs in p53-induced apoptosis: Activation of the vertebrate homologue of the Drosophila seven in absentia gene. Proc. Natl. Acad. Sci. USA 93: 3953-3957

19. Fiscella M, Zhang H, Fan S, Sakaguchi K, Shen S, Mercer WE, Vande Woude GF, O'Connor PM and Appella E (1997) Wip1, a novel human protein phosphatase that is induced in response to ionizing radiation in a p53-dependent manner. Proc. Natl. Acad. Sci. USA 94: 6048-6053

20. Willerford DM, Chen J, Ferry JA, Davidson L, MA A and Alt FW (1995) Interleukin2 receptor alpha chain regulates the size and content of the peripheral lymphoid compartment. Immunity 3: 521-530

21. Bonnema JD, Karnitz LM, Schoon RA, Abraham RT and Leibson PJ (1994) Fc receptor stimulation of phosphatidylinositol 3-kinase in natural killer cells is associated with protein kinase C-independent granule release and cellmediated cytotoxicity. J. Exp. Med. 180: 1427-1435

22. Li P, Nijhawan D, Budihardjo I, Srinivasula SM, Ahmad M, Alnemri ES and Wang X (1997) Cytochrome $c$ and dATP-dependent formation of Apaf-1/caspase-9 complex initiates an apoptotic protease cascade. Cell 91: 479-489

23. Susin SA, Zamzami N, Castedo M, Hirsch T, Marchetti P, Macho A, Daugas E, Geuskens M and Kroemer G (1996) Bcl-2 inhibits the mitochondrial release of an apoptogenic protease. J. Exp. Med. 184: 1331-1341

24. Messika EJ, Lu PS, Sung YJ, Yao T, Chi JT, Chien YH and Davis MM (1998) Differential effect of B lymphocyte-induced maturation protein (Blimp-1) expression on cell fate during B cell development. J. Exp. Med. 188: 515-525 
25. Yonish-Rouach E, Grunwald D, Wilder S, Kimchi A, May E, Lawrence JJ, May P and Oren M (1993) p53-mediated cell death: relationship to cell cycle control. Mol. Cell. Biol. 13: 1415-1423

26. Matsuzawa S, Takayama S, Froesch BA, Zapata JM and Reed JC (1998) p53inducible human homologue of Drosophila seven in absentia (Siah) inhibits cell growth: suppression by BAG-1. EMBO J. 17: 2736-2747

27. Donnadieu E, Trautmann A, Malissen M, Trucy J, Malissen B and VivierE (1994) Reconstitution of CD3 zeta coupling to calcium mobilization via genetic complementation. J. Biol. Chem. 269: 32828-32834

28. Yonish-Rouach E, Resnitzky D, Lotem J, Sachs L, Kimchi A and Oren M (1991) Wild-type p53 induces apoptosis of myeloid leukaemic cells that is inhibited by interleukin-6. Nature 352: 345-347

29. Castrillon DH and Wasserman SA (1994) Diaphanous is required for cytokinesis in Drosophila and shares domains of similarity with the products of the limb deformity gene. Development 120: 3367-3377

30. Sudol M, Bork P, Einbond A, Kastury K, Druck T, Negrini M, Huebner K and Lehman D (1995) Characterization of the mammalian YAP (Yes-associated protein) gene and its role in defining a novel protein module, the WW domain. J. Biol. Chem. 270: 14733-14741

31. Bork P and Sudol M (1994) The WW domain: a signalling site in dystrophin? Trends Biochem. Sci. 19: 531-533

32. Frazier JA and Field CM (1997) Actin cytoskeleton: are FH proteins local organizers? Curr. Biol. 7: R414-R417

33. Wasserman S (1998) FH proteins as cytoskeletal organizers. Trends Cell. Biol. 8: $111-115$

34. Woychik RP, Stewart TA, Davis LG, D'Eustachio P and Leder P (1985) An inherited limb deformity created by insertional mutagenesis in a transgenic mouse. Nature 318: $36-40$
35. Chan DC, Wynshaw-Boris A and Leder P (1995) Formin isoforms are differentially expressed in the mouse embryo and are required for normal expression of fgf-4 and shh in the limb bud. Development 121: 3151-3162

36. Magnuson T and Epstein CJ (1984) Oligosyndactyly: a lethal mutation in the mouse that results in mitotic arrest very early in development. Cell 38: 823-833

37. Zeller R, Jackson-Grusby $L$ and Leder $P$ (1989) The limb deformity gene is required for apical ectodermal ridge differentiation and anteroposterior limb pattern formation. Genes Dev. 3: 1481-1492

38. Vogt TF, Jackson-Grusby L, Rush J and Leder P (1993) Formins: phosphoprotein isoforms encoded by the mouse limb deformity locus. Proc. Natl. Acad. Sci. USA 90: 5554-5558

39. Irusta PM and DiMaio D (1998) A single amino acid substitution in a WW-like domain of diverse members of the PDGF receptor subfamily of tyrosine kinases causes constitutive receptor activation. EMBO J. 17: 6912-6923

40. Ogasawara J, Watanabe-Fukunaga R, Adachi M, Matsuzawa A, Kasugai T, Kitamura Y, Itoh N, Suda T and Nagata S (1993) Lethal effect of the anti-Fas antibody in mice. Nature 364: 806-809

41. Leo O, Foo M, Sachs DH, Samelson LE and Bluestone JA (1987) Identification of a monoclonal antibody specific for a murine T3 polypeptide. Proc. Natl. Acad. Sci. USA 84: $1374-1378$

42. Luciani MF and Chimini G (1996) The ATP binding cassette transporter ABC1, is required for the engulfment of corpses generated by apoptotic cell death. EMBO J. 15: $226-235$

43. Bouvier G, Watrin F, Naspetti M, Verthuy C, Naquet $P$ and Ferrier P (1996) Deletion of the mouse T-cell receptor beta gene enhancer blocks alphabeta Tcell development. Proc. Natl. Acad. Sci. USA 93: 7877-7881

44. Altschul SF, Gish W, Miller W, Myers EW and Lipman DJ (1990) Basic local alignment search tool. J. Mol. Biol. 215: 403-410. 